\title{
A Comprehensive Approach for the Ergonomic Evaluation of 13 Emergency and Transport Ventilators
}

\author{
Nicolas Marjanovic MD and Erwan L'Her MD PhD
}

\begin{abstract}
BACKGROUND: Mechanical ventilation is an important part of emergency medicine and is frequently used for transportation. Human errors during ventilator settings are frequent and may be associated with high morbidity/mortality. The aim of the study was to provide a complete ergonomic evaluation of emergency and transport ventilators, taking into account objective and subjective human-machine interface assessments and individual mental work load. METHODS: We performed a prospective bench ergonomic evaluation of 13 emergency and transport ventilators, using standardized conditions and a global methodological approach. The study was performed in an evaluation laboratory dedicated to respiratory care, and 12 emergency physicians unfamiliar with the tested devices were included in the evaluation. The ventilators were classified into 3 categories (simple, sophisticated, and ICU-like). Objective chronometric evaluations were conducted considering 9 tasks, and subjective evaluations were performed (ease of use, willingness to use, and user-friendliness of monitoring) using Likert scales. Mental work load evaluation was performed using the NASA Task Load Index scale. RESULTS: Overall task failure rate represented $4 \%$ of all attempts. Setting modifications, ventilation mode changes, and powering down durations were different between simple and other emergency and transport ventilator categories $(P<.005)$. There was no difference between ventilator categories for the ease of use and userfriendliness of the monitoring. In contrast, the willingness to use was lower for simple devices, compared with sophisticated and ICU-like emergency and transport ventilators $(2.9 \pm 1.4$ vs $3.9 \pm 1.2, P=.002$ and $4.3 \pm 1, P<.001)$. No differences were observed between devices regarding the mental work load, except for several specific devices in the sophisticated category. CONCLUSIONS: A comprehensive ergonomic evaluation provides valuable information while investigating operational friendliness in emergency and transport ventilators. The choice of a device not only depends on its technical characteristics but should take into account its clinical operational setting and ergonomics in order to decrease mental work load. Sophisticated emergency and transport ventilators should only be used by clinicians who demonstrate expertise in mechanical ventilation. Key words: bench; emergency ventilators; ergonomics; mental workload. [Respir Care 2016;61(5):632-639. (c) 2016 Daedalus Enterprises]
\end{abstract}

\section{Introduction}

Mechanical ventilation is an important part of emergency medicine practice and is frequently used for pre-

Dr Marjanovic is affiliated with Urgences Adultes, CHRU de Brest, Brest Cedex, France. Dr L'Her is affiliated with Réanimation Médicale, CHRU de Brest, Brest Cedex, France and CESIM/LATIM INSERM UMR 1101, Université de Bretagne Occidentale, Rue Camille Desmoulins, Brest, France.

Dr L'Her discloses relationships with Air Liquide, Maquet, Smiths Medical, and Oxy'nov Inc. Dr Marjanovic discloses a relationship with Weinmann. hospital and in-hospital transportation. ${ }^{1}$ Patients who require mechanical ventilation are fragile, and one single ventilator setting or monitoring error may induce patient deterioration. These human errors are frequent and may be associated with high morbidity and mortality.2,3

Correspondence: Erwan L'Her MD PhD, CESIM/LATIM UMR 1101, Faculté de Médecine, Rue Camille Desmoulins, 29200 Brest, France. E-mail: erwan.lher@chu-brest.fr.

DOI: $10.4187 /$ respcare.04292 
An optimal device for emergency care should provide adequate technical performance, combined with optimal ergonomics (ie, an easy-to-use and user-friendly human/machine interface) ${ }^{4,5}$ Significant improvement in the technical performance of emergency and transport ventilators has been observed during the last decade, ${ }^{6}$ and more recent devices have demonstrated technical performance similar to that of ICU ventilators. ${ }^{7}$ Although older generation emergency and transport ventilators usually display low performance and are the cheapest devices, they also provide little monitoring and a rather simple human/machine interface. More recent emergency and transport ventilators do provide a more evolved human/machine interface as well as depicting ventilator curves. ${ }^{5,6}$ Four studies have demonstrated that the human/machine interface design could be associated with user error and a delay in the performance of basic tasks. ${ }^{1,8-10}$ However, an objective comparison of emergency and transport ventilators should also take into account the fact that devices significantly differ in terms of technology and cost and cannot all be compared with each other. Most studies that have analyzed emergency and transport ventilator ergonomics have focused mainly on chronometric measurements and task failure assessments. ${ }^{1,8-11}$ The purpose of this study was to provide a complete ergonomic evaluation of 13 emergency and transport ventilators, taking into account objective and subjective human/machine interface tests and mental work load evaluation using a multidimensional NASA task load index (NASA-TLX) test.

\section{Methods}

The health-care system in France does not include respiratory therapists. All of the subjects submitted to the investigation were emergency physicians, who are routinely responsible for emergency and transport ventilator settings and modifications. Twelve emergency physicians were included in the evaluation to test the devices in a randomized order. It was not considered possible for each physician to test all ventilators because of time constraints, but all of the subjects were supposed to test at least 6 different devices. All of the physicians were supposed to have prior knowledge of mechanical ventilation but to be unfamiliar with the tested machines except for the Oxylog 3000 and Vela, which were in use in our emergency department.

\section{Ventilator Characteristics}

Thirteen emergency and transport ventilators were evaluated and classified into 3 categories, as described previously. ${ }^{7}$ Briefly, simple ventilators are emergency and transport ventilators delivering one or 2 ventilatory modes, mostly without noninvasive ventilation capabilities; sophisticated emergency and transport ventilators usually en-

\section{QUICK LOOK}

\section{Current knowledge}

Mechanical ventilation is an important part of emergency medicine practice. Human errors during ventilatory settings and monitoring are frequent and may be related to non-optimal human to machine interface.

\section{What this paper contributes to our knowledge}

This experimental bench study aimed to provide an extensive ergonomic evaluation of actual emergency and transport ventilators, taking into account objectivesubjective human/machine interface assessments and mental workload. The choice of a device depends on its technical characteristics but should also take into account comprehensive ergonomics to decrease the operational failure rate. Sophisticated emergency and transport ventilator devices and interfaces may have increased difficulty of use for basic operational tasks. Human/machine interface design in close collaboration with clinicians is mandatory to improve their ease of use and security of care.

able noninvasive ventilation and pressure/volume curve visualization; and ICU-like emergency and transport ventilators are emergency and/or stabilization unit devices that cannot be routinely used for transportation because of their weight and size. Nine devices were kindly provided by manufacturers, and the others were provided by the biomedical departments of our institutions.

\section{Objective Task Completion Evaluation}

Nine specific tasks were considered: (1) circuit installation (connection of the circuit to the ventilator and a test simulator); (2) mode recognition (exact reading of the ventilator mode set by the investigators); (3) ventilator settings reading (tidal volume-positive inspiratory pressure + PEEP $+\mathrm{F}_{\mathrm{IO}_{2}}+$ ventilatory rate or trigger value); (4) ventilator setting modification (from 500 to $600 \mathrm{~mL}$ for tidal volume or from 10 to $15 \mathrm{~cm} \mathrm{H}_{2} \mathrm{O}$ for PIP); (5) PEEP modification (from 5 to $10 \mathrm{~cm} \mathrm{H}_{2} \mathrm{O}$ ); (6) ventilator mode modification (from VC-CMV to noninvasive PC-CSV or from noninvasive PC-CSV to VC-CMV); (7) alarm parameter reading (reading of alarm settings); (8) alarm shutdown (identification of the message and shutdown); (9) ventilator extinction (complete emergency and transport ventilator powering down). A preliminary defined written script for tasks/questions was used to ensure the consistent treatment of each study subject.

For each task, the physicians were allowed only one attempt, and an arbitrary upper time limit was chosen; the 
correct response was to be given in $<180 \mathrm{~s}^{1,7}$ The test was considered a failure if the physicians did not provide a correct answer or if they answered after the upper limit.

\section{Subjective User-Friendliness Evaluation}

Three subjective components were evaluated by the physicians using easy questions, from the ease of use (How easy was the device to use?) to the willingness to use (Do you wish to use this device in a clinical routine situation?) and the user-friendliness of the monitoring (How do you evaluate the monitoring user-friendliness of this device?). The answers to each of these components were ranked using Likert scales, ranging from 1 (worst value) to 5 (best value).

\section{Mental Work Load Evaluation}

Mental work load is a subjective ergonomic measurement, which assesses the combination of 2 parameters involved in a failure: human factors and human/machine interface. Mental work load is used as a valid and reproducible indicator for human/machine interface development and comparison. ${ }^{12,13}$ Mental work load monitoring enables the depiction of differences that will not be observed when using standard objective and subjective tests. NASA-TLX is a multidimensional tool that was developed by the National Aeronautics and Space Administration's Ames Research Center in 1986 and validated in 1988 for perceptual work load evaluations using task-load index (TLX) measurement. ${ }^{14,15}$

NASA-TLX explores 6 different psychological dimensions that are involved in mental work load: mental demand, temporal demand, physical demand, frustration, performance, and effort. These bidimensional Likert-type scales are used to obtain a rating for these dimensions, and a score ranging from 0 to 100 is obtained on each scale. These subscales are subsequently individually weighed by letting the subject compare them pairwise, based on their perceived importance, to obtain a TLX result. The higher the TLX, the higher the mental work load, with the human/machine interface being considered as difficult to use.

\section{Statistical Analysis}

Values are given as mean $\pm \mathrm{SD}$, unless otherwise specified. Data were compared using the chi-square test for qualitative parameters and non-parametric tests for quantitative parameters. $P<.05$ was considered statistically significant. Analyses were performed using SPSS 21 (IBM Corporation, Armonk, New York).

\section{Results}

\section{Ventilator Characteristics}

Thirteen emergency and transport ventilators were evaluated, 4 of which were considered as simple, 6 as sophisticated, and 3 as ICU-like emergency and transport ventilators. No simple device provided a screen (except for the Osiris 2) or curve visualization. All sophisticated and ICUlike emergency and transport ventilators had screens with settings and curve control except for the HT70, which only enabled setting control on its screen. The ventilators' characteristics are provided in Table 1. All of these devices are already commercialized and used in European emergency departments. Twelve emergency physicians were included in the evaluation, and each device was tested 11 times.

\section{Objective Task Completion Evaluation}

Table 2 presents the overall task failure rate, which represents $4 \%$ of all attempts. Several evaluations were not possible due to the devices' characteristics: ventilation mode changes for the Osiris 2 and Medumat Standard A and PEEP modification for the Medumat Standard A. Setting modifications, mode changes, and emergency and transport ventilator offset durations were different between simple and other emergency and transport ventilator categories $(P<.005)$ (Fig. 1$)$.

The failure rate was different between the categories $(P=.02)$, but there were no differences between sophisticated and simple emergency and transport ventilators ( 25 of 486 vs 9 of $301, P=.14$ ). Most of the failures occurred with sophisticated ventilators ( $73 \%$ of all failures), during setting readings $(6 \%)$, alarm setting readings $(8 \%)$, and mode changes (7\%). The Oxylog 3000 represented a large part of the overall failures (28\%). We did not observe any differences between emergency and transport ventilators regarding a specific task, except for mode changes $(P<.001)$.

\section{Subjective User-Friendliness Evaluation}

The Medumat standard 2, Hamilton T1, and Monnal T75 gave the best results for all of the tests, and the Osiris 2, HT70, and BellaVista gave the worst. There were no significant differences between ventilator categories for the ease of use and monitoring user-friendliness. However, willingness to use was lower for simple compared with sophisticated and ICU-like emergency and transport ventilators $(2.9 \pm 1.4$ vs $3.9 \pm 1.2, P=.002$ and $4.3 \pm 1$, $P<.001$, respectively). When emergency and transport ventilators enabled ventilation curve monitoring (all sophisticated and ICU-like emergency and transport ven- 
Table 1. Ventilator Characteristics and Classifications

\begin{tabular}{|c|c|c|c|c|c|c|c|c|}
\hline Ventilator & Technology & Circuit & Screen & $\begin{array}{l}\text { Curve } \\
\text { Monitoring }\end{array}$ & Ventilatory Modes & $\begin{array}{l}\text { NIV } \\
\text { Mode }\end{array}$ & $\begin{array}{l}\text { Tactile } \\
\text { Interface }\end{array}$ & Company \\
\hline \multicolumn{9}{|l|}{ Simple } \\
\hline Medumat Standard A & Pneumatic & Mono & No & No & VC-CMV & No & No & $\begin{array}{l}\text { Weinmann (Hamburg, } \\
\text { Germany) }\end{array}$ \\
\hline Medumat Standard 2 & Pneumatic & Mono & Yes & No & VC-CMV & No & No & Weinmann \\
\hline Osiris 2 & Pneumatic & Mono & Yes & No & VC-CMV, PC-CSV & No & No & Air Liquide (Antony, France) \\
\hline Oxylog 2000 & Pneumatic & Mono & Yes & No & VC-CMV, PC-CSV & No & No & Dräger (Lübeck, Germany) \\
\hline \multicolumn{9}{|l|}{ Sophisticated } \\
\hline Elisée 350 & Turbine & Mono/dual & Yes & Yes & $\begin{array}{l}\text { VC-CMV, VC-IMV, PC-CMV, } \\
\text { PC-IMV, PC-CSV }\end{array}$ & Yes & Yes & Resmed (Saint Priest, France) \\
\hline HT70 & Piston & Mono/dual & Yes & No & $\begin{array}{l}\text { VC-CMV, VC-IMV, PC-CMV, } \\
\text { PC-IMV, PC-CSV }\end{array}$ & Yes & No & $\begin{array}{l}\text { Covidien (Mansfield, } \\
\text { Massachusetts) }\end{array}$ \\
\hline Medumat Transport & Pneumatic & Mono & Yes & Yes & $\begin{array}{l}\text { VC-CMV, VC-IMV, PC-CMV, } \\
\text { PC-IMV, PC-CSV }\end{array}$ & Yes & No & Weinmann \\
\hline Oxylog 3000 & Pneumatic & Mono & Yes & Yes & VC-CMV, PC-IMV, PC-CSV & Yes & No & Dräger \\
\hline $\mathrm{T} 1$ & Turbine & Dual & Yes & Yes & $\begin{array}{l}\text { VC-CMV, VC-IMV, PC-CMV, } \\
\text { PC-IMV, PC-CSV }\end{array}$ & Yes & Yes & $\begin{array}{l}\text { Hamilton (Bonaduz, } \\
\text { Switzerland) }\end{array}$ \\
\hline Monnal T60 & Turbine & Dual & Yes & Yes & $\begin{array}{l}\text { VC-CMV, VC-IMV, PC-CMV, } \\
\text { PC-IMV, PC-CSV }\end{array}$ & Yes & Yes & Air Liquide \\
\hline \multicolumn{9}{|l|}{ ICU-like } \\
\hline Vela & Turbine & Dual & Yes & Yes & $\begin{array}{l}\text { VC-CMV, VC-IMV, PC-CMV, } \\
\text { PC-IMV, PC-CSV }\end{array}$ & Yes & Yes & $\begin{array}{l}\text { Viasys Carefusion } \\
\text { (San Diego, California) }\end{array}$ \\
\hline Bellavista & Turbine & Dual & Yes & Yes & $\begin{array}{l}\text { VC-CMV, VC-IMV, PC-CMV, } \\
\text { PC-IMV, PC-CSV }\end{array}$ & Yes & Yes & IMT (Buchs, Switzerland) \\
\hline Monnal T75 & Double & Dual & Yes & Yes & $\begin{array}{l}\text { VC-CMV, VC-IMV, PC-CMV, } \\
\text { PC-IMV, PC-CSV }\end{array}$ & Yes & Yes & Air Liquide \\
\hline
\end{tabular}

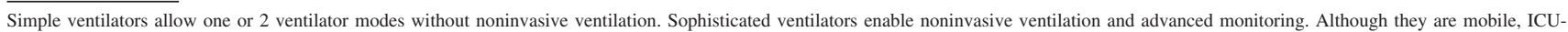
like ventilators could not be used routinely for transportation because of their size and weight.

NIV = noninvasive ventilation

$\mathrm{VC}-\mathrm{CMV}=$ volume-control continuous mandatory ventilation

$\mathrm{PC}-\mathrm{CSV}=$ pressure-control continuous spontaneous ventilation

VC-IMV $=$ volume-control intermittent mandatory ventilation

PC-CMV = pressure-control continuous mandatory ventilation

PC-IMV $=$ pressure-control intermittent mandatory ventilation

tilators except for the HT70), monitoring user-friendliness was considered significantly better $(3.9 \pm 1$ vs $3.3 \pm 1.2, P=.012)$, and willingness to use was higher $(P<.001)$.

\section{Mental Work Load Evaluation}

The mean NASA-TLX index was $48.7 \pm 17.9$, and the results of each dimension are presented in Figure 2 and Table 3. The Newport HT70 gave the highest TLX value, and the Viasys Vela gave the lowest. TLX ventilator categories were $47.6 \pm 20$ for simple, $50.2 \pm 17.1$ for sophisticated, and $42.8 \pm 34$ for ICU-like emergency and transport ventilators, without any statistical difference, either for the global index or for the various dimensions, except in the sophisticated category. The Newport HT70 and Dräger Oxylog 3000 tests depicted a higher global NASA-TLX than the other devices $(61 \pm 7.8, P<.05$ and $62 \pm 18.4, P<.05$ ) (Table 3). Higher frustration and effort dimensions were observed with the Newport HT70 $(P<.05)$.

\section{Discussion}

Our global approach regarding emergency and transport ventilators ergonomics enabled us to demonstrate several interesting features. Some devices presented poor characteristics that may lead to delayed user-interface interaction or even to complete task failure. Although the newer and sophisticated emergency and transport ventilators were usually more appreciated by users than the simple and older ones, mental work load-specific dimensions, task failure rates, and objective time-test durations were significantly higher for some of them. Mental work load monitoring enabled differences to be depicted that might not have been observed when only using standard objective and subjective tests. Sophisticated devices, which are routinely used in most emergency departments, would benefit from 
Table 2. Task Failure Rate and User-Friendliness Subjective Assessment

\begin{tabular}{|c|c|c|c|c|}
\hline \multirow{2}{*}{ Ventilator } & \multirow{2}{*}{$\begin{array}{c}\text { Task Failure Rate, } \\
\% \text { of Attempts }\end{array}$} & \multicolumn{3}{|c|}{ Subjective User-Friendliness Test Score, Mean \pm SD (Range) } \\
\hline & & Ease of Use & Monitoring User-Friendliness & Willingness to Use* \\
\hline \multicolumn{5}{|l|}{ Simple } \\
\hline Medumat Standard A & 6 & $3.7 \pm 1.1(2-5)$ & $4 \pm 1.2(2-5)$ & $2.3 \pm 1.1(1-4)$ \\
\hline Medumat Standard 2 & 3 & $4 \pm 1.4(2-5)$ & $3.8 \pm 1(3-5)$ & $4 \pm 0.8(3-5)$ \\
\hline Osiris & 0 & $3.6 \pm 1.6(2-5)$ & $2 \pm 0.8(1-3)$ & $1.5 \pm 0.6(1-2)$ \\
\hline Oxylog 2000 & 2 & $3.7 \pm 0.9(3-5)$ & $3.1 \pm 1.2(2-5)$ & $3.7 \pm 1.4(1-5)$ \\
\hline All simple ventilators & 3 & $3.7 \pm 1.1(2-5)$ & $3.4 \pm 1.3(1-5)$ & $2.9 \pm 1.4(1-5)$ \\
\hline \multicolumn{5}{|l|}{ Sophisticated } \\
\hline Elisee 350 & 6 & $3.4 \pm 1(2-5)$ & $3.4 \pm 1(2-5)$ & $3.4 \pm 1.5(1-5)$ \\
\hline HT70 & 10 & $2.8 \pm 1(1-4)$ & $2.9 \pm 0.7(2-4)$ & $2.6 \pm 1.2(1-4)$ \\
\hline Medumat Transport & 1 & $4 \pm 0.8(3-5)$ & $4.3 \pm 0.8(3-5)$ & $4.5 \pm 0.7(3-5)$ \\
\hline Oxylog 3000 & 12 & $3.3 \pm 1.2(2-5)$ & $3 \pm 1.1(1-4)$ & $3.3 \pm 1.3(1-5)$ \\
\hline $\mathrm{T} 1$ & 0 & $4.7 \pm 0.5(4-5)$ & $4.7 \pm 0.5(4-5)$ & $4.5 \pm 0.5(4-5)$ \\
\hline $\mathrm{T} 60$ & 6 & $4 \pm 0.5(3-5)$ & $4.2 \pm 1(3-5)$ & $4.7 \pm 0.5(4-5)$ \\
\hline All sophisticated ventilators & 6 & $3.7 \pm 1(1-5)$ & $3.8 \pm 1.1(1-5)$ & $3.9 \pm 1.2(1-5)$ \\
\hline \multicolumn{5}{|l|}{ ICU-like } \\
\hline Vela & 0 & $4.2 \pm 0.8(3-5)$ & $3.9 \pm 0.5(3-4,5)$ & $4.6 \pm 0.8(3-5)$ \\
\hline BellaVista & 2 & $2.9 \pm 1.1(2-4,5)$ & $3.2 \pm 1.5(2-5)$ & $3.4 \pm 1.3(2-5)$ \\
\hline $\mathrm{T} 75$ & 1 & $4.2 \pm 0.5(3,5-5)$ & $4.4 \pm 0.8(3-5)$ & $4.7 \pm 0.4(4-5)$ \\
\hline All ICU-like ventilators & 1 & $3.8 \pm 0.9(2-5)$ & $3.9 \pm 1.1(2-5)$ & $4.3 \pm 1(2-5)$ \\
\hline Average & 4 & $3.7 \pm 1(1-5)$ & $3.6 \pm 1.1(1-5)$ & $3.6 \pm 1.3(1-5)$ \\
\hline $\begin{array}{l}\text { Measurements were performed using Lik } \\
1 \text { (certainly not) to } 5 \text { (certainly). Ventila } \\
\text { emergency and transport Ventilator cates } \\
* P=.037 \text {. }\end{array}$ & $\begin{array}{l}\text { were not different in } \\
\text { willingness to use su }\end{array}$ & $\begin{array}{l}5 \text { (very easy); mon } \\
\text { ease of use and mo }\end{array}$ & $\begin{array}{l}\text { endliness: } 1 \text { (very difficult) to } 5 \text { (ver } \\
\text { riendliness. There was a statistically }\end{array}$ & $\begin{array}{l}\text { lingness to use scale: } \\
\text { lifference between }\end{array}$ \\
\hline
\end{tabular}

improved human/machine interface evaluation, at least regarding task failure reduction.

\section{Emergency and Transport Ventilator Category Comparison}

ICU-like ventilators are too bulky and heavy to be routinely used for emergency transportation. However, these devices are commercially available in Europe for specific use in emergency departments and are sometimes used for transportation of the most critically ill patients. This is the reason why they were considered for evaluation in a specific category. The results that are presented herein are to be considered by taking into account each category with respect to the other, depending on the clinical use of the device.

Significant differences were observed in terms of the task failure rate and objective chronometric tests for simple compared with sophisticated and ICU-like emergency and transport ventilators. Most test failures with the sophisticated emergency and transport ventilators were observed during the ventilatory mode changes, compared with other categories. This difference could be explained by the fact that only a few settings and modes are available on simple devices, whereas many more possibilities and confirmation steps are necessary for the other 2 categories. ${ }^{5}$ Sophisticated and ICU-like emergency and transport ventilators also need 2 or 3 steps to power off, whereas simple devices only need a single button switch. In 2 previous studies, ${ }^{8,9}$ the median time periods necessary to perform similar steps were found to be higher, whereas the same trends were observed in home-care ventilators in terms of user-friendliness. ${ }^{10}$ Emergency and transport ventilator human/machine interfaces have only marginally evolved over time, and most current devices are somewhat similar from one brand to the other, which may explain such results among a population of well-trained emergency physicians.

Concerning sophisticated emergency and transport ventilators, there was also frequent confusion between spontaneous noninvasive ventilation and invasive ventilation modes, when such an option had to be selected. Another frequent cause of failure was confusion between volumecontrol continuous mandatory ventilation (VC-CMV) and volume-control intermittent mandatory ventilation (VCIMV) modes. Indeed, VAC (for "volume assisté contrôlé"), the French acronym that is routinely used (corresponding to VC-CMV) is quite similar to VACI (for "volume assisté contrôlé intermittent," corresponding to VC-IMV). Another example, the HT70 ventilatory modes, only display 


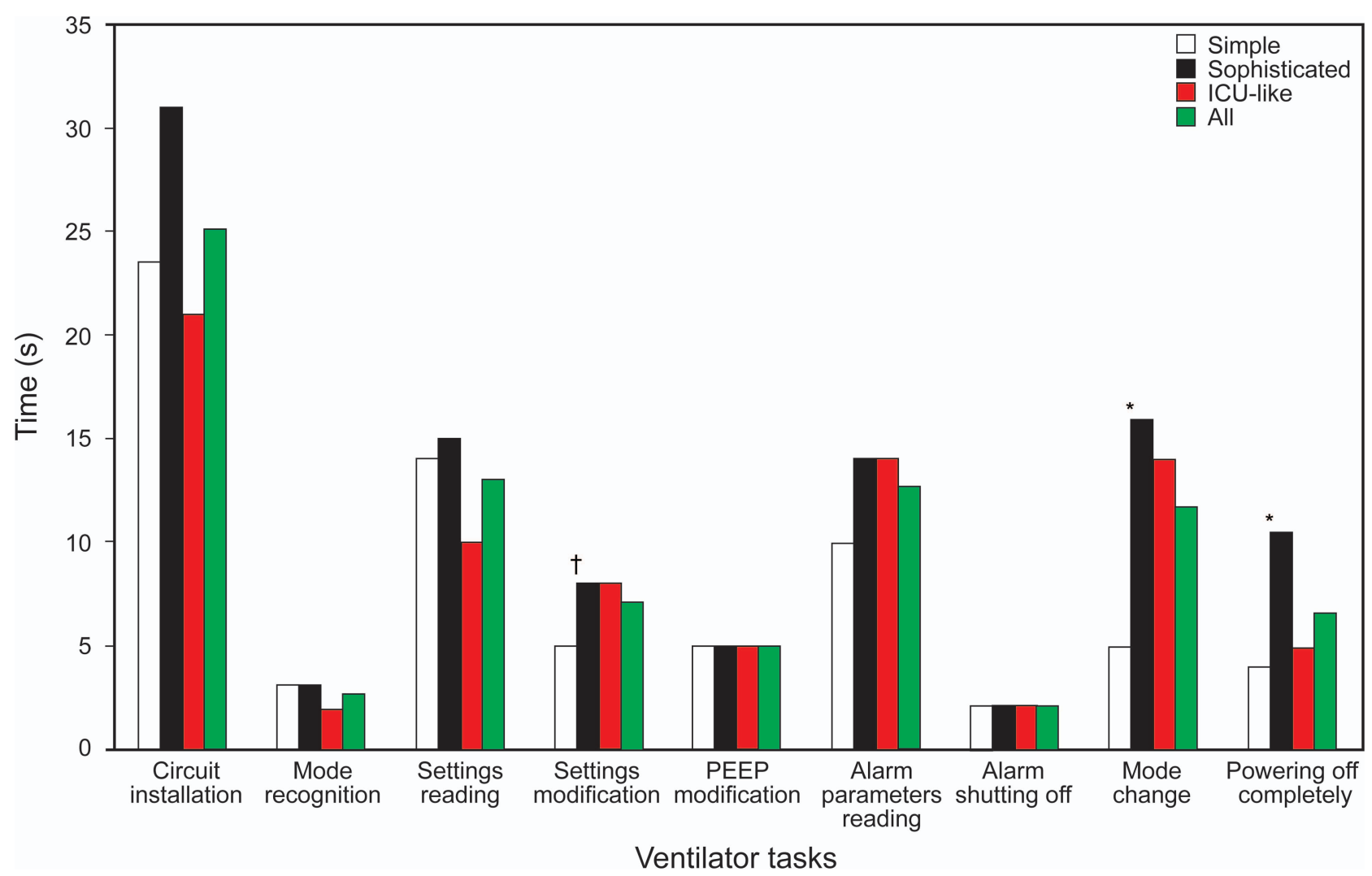

Fig. 1. Data bars represent the median time to complete the ventilator setup and adjustments. After $180 \mathrm{~s}$, a task was considered as failed. Mode change and ventilator offset were the shortest for simple emergency/transport ventilators, compared to other categories. Settings modification was the shortest for simple vs. sophisticated ventilators only. ${ }^{*}, P<.005 ; \dagger, P=.003$.

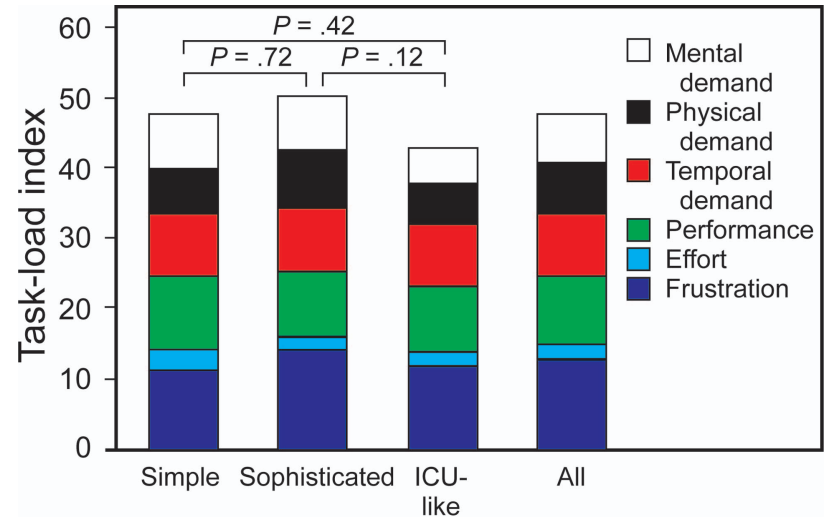

Fig. 2. Task-load index data bars and NASA-TLX perceptual workload dimensions. Data bars represent mean task load index for the emergency/transport ventilator categories. Mean task load index of simple ventilators $(47.6 \pm 20.8)$, sophisticated ventilators $(50.2 \pm$ 17.1) and ICU-like ventilators $(42.8 \pm 15.9)$ were similar $(P=.34)$.

English acronyms, and as a result, VC-IMV was frequently mistaken for noninvasive ventilation modes. This type of failure has already been observed by Templier et al. ${ }^{1}$ Thus, it clearly seems necessary to standardize the terminology and to simplify mode recognition in order to avoid such failures ${ }^{1,8-10,16}$ but also to ensure that the device's human/machine interface is fully adapted to the users' experience and country. With regard to simple emergency and transport ventilators, the failures mainly concerned setting and alarm readings and were considered to be linked to poor monitoring precision.

\section{Mental Work Load Assessment}

Mental work load assessment is a modern cognitive psychology tool that provides a new dimension in evaluating the ergonomics of biomedical devices. ${ }^{14}$ As already proved in other fields of interest, it can depict significant differences between devices that would not have been noticed using standard tests. ${ }^{15}$

As observed in our study, a combination of buttons is frequently required to start or stop a function, the labeling of the buttons may not always be clear, and screens are often absent or somewhat difficult to read. Such problems, which are difficult to explore using standard ergonomic tests, may be evaluated when detailing the different mental work load dimensions, such as performance, effort, or mental demand. Mental work load assessment also enables us to understand why, besides optimal screen monitoring capabilities and/or technical properties, several devices may 


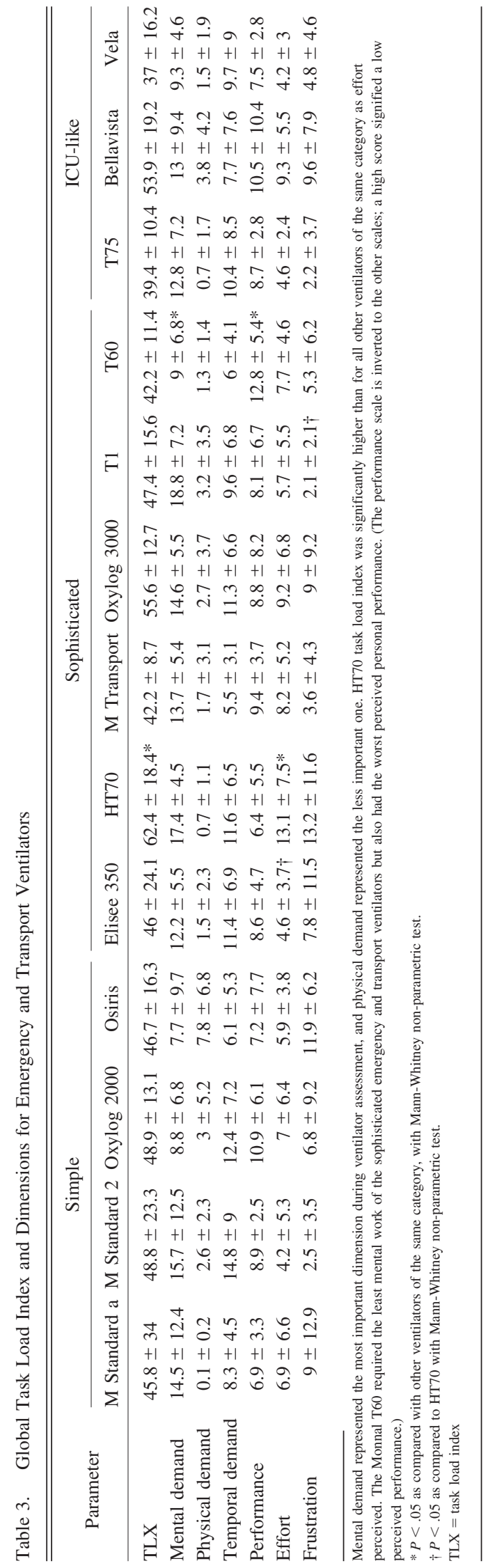

induce significant mental overload and/or failures due to an increase in the number of steps required to complete a single task.

\section{Human/Machine Interface Differences and the Potential Impact on Task Failure Rate Reduction}

It is common in clinical routine that a clinician may operate a specific ventilator without sufficient training, apart from some basic knowledge in mechanical ventilation. Medical errors have been demonstrated to be major determinants in patient safety since the "to err is human" report published in $1999,{ }^{17}$ and errors related to mechanical ventilation occur with the greatest frequency. ${ }^{2}$ Confusing human/machine interface aspects, designed without sufficient input from the end users, may lead to inadequate solutions in the clinical setting.

Although our results may not be totally conclusive, the screen interface and the availability of curve monitoring were associated with a better perceived user-friendliness and willingness to use, which may thus indirectly affect the task failure rate despite the fact that simple devices also led to fewer task failures. Similar results have already been observed by Uzawa et al, ${ }^{8}$ who took into account 4 modern ICU ventilators and observed that different human/machine interface designs resulted in different rates of operational failures.

Technological improvements have led to significant improvements in mechanical ventilator performance over recent decades. ${ }^{6}$ According to the literature, the most recent sophisticated emergency and transport ventilators do actually have technical capacities closer to those of standard ICU devices. ${ }^{7,18}$ The technological evolution of more complex devices should also be accompanied by the emergence of evolved human/machine interfaces, in order to decrease mental work load and reduce task failures. ${ }^{19}$ Biomedical systems and ergonomic improvements are necessary to generate the appropriate design requirements, in response to health-care constraints, ${ }^{20}$ and such ergonomic studies with sufficient input from clinicians should be a priority for manufacturers.

\section{Limitations of the Study}

Our study suffers from several limitations. First, as also proposed by several investigators, ${ }^{1,8-10}$ the subjects were not supposed to have any operational experience in using most of the models in the study, since for all basic operational tasks, the clinicians should not have referred to the operating instructions for the sake of task failure reduction, especially in the case of emergency. One may consider that this study also demonstrates that proper training for practitioners is mandatory. However, although some devices (Oxylog 3000 and Vela) were already known to 


\section{EMERGENCY AND TRANSPORT Ventilator ERGONOMics}

some of the users and may therefore have been considered as references, a huge failure rate was witnessed using the Oxylog 3000, which demonstrated that ergonomic improvements are also mandatory. Second, the NASA-TLX results should be considered with caution because ergonomic assessment and mental work load are new notions in emergency practice, and NASA-TLX is a difficult test to interpret. ${ }^{13}$ Before each test and for each participant, we explained the progress analyses and the fact that it was emergency and transport ventilator ergonomics that was being evaluated and not the physicians' own capabilities. Finally, we used a computerized NASA-TLX version, which has been associated with a higher mental work load value than the paper-and-pencil version. ${ }^{21}$

\section{Conclusions}

Our global ergonomic assessment confirmed as in the literature that the human/machine interface design and the user-friendliness of ventilators are relevant to the occurrence of operational failures and increased mental work load. According to their technical performances and characteristics, ${ }^{7,22}$ sophisticated emergency and transport ventilators should be privileged in emergency medicine and transportation. However, monitoring capabilities and the multiplication of options and parameters increase the difficulty of use for basic operational tasks. Human/machine interface design in close collaboration with clinicians, monitoring simplification, and terminology standardization may reduce most of these failures. Specific training is necessary as well as the provision of optimal technological performance. The future assessment of mental work load should increasingly take into account the hands-on human/ machine interface experience of clinicians.

\section{ACKNOWLEDGMENTS}

We acknowledge the help of emergency physicians from Brest University Hospital who made this bench evaluation possible and supported us on several occasions during the past years. We also thank the manufacturers who kindly provided devices for the evaluation.

\section{REFERENCES}

1. Templier F, Miroux P, Dolveck F, Descatha A, Goddet NS, Jeleff C, et al. Evaluation of the ventilator-user interface of 2 new advanced compact transport ventilators. Respir Care 2007;52(12):1701-1709.

2. Giraud T, Dhainaut JF, Vaxelaire JF, Joseph T, Journois D, Bleichner $\mathrm{G}$, et al. Iatrogenic complications in adult intensive care units: a prospective two-center study. Crit Care Med 1993;21(1):40-51.
3. Bracco D, Favre JB, Bissonnette B, Wasserfallen JB, Revelly JP, Ravussin P, Chioléro R. Human errors in a multidisciplinary intensive care unit: a 1-year prospective study. Intensive Care Med 2001; 27(1):137-145.

4. Templier F. Particular aspects of mechanical ventilation in emergency medicine. ITBM-RBM 2005;26:28-34.

5. Damm C, Clabault K, Lamia B, Richard JC. Caractéristiques d'un bon ventilateur de transport. Réanimation 2003;12(7):502-509.

6. Richard JC, Kacmarek RM. ICU mechanical ventilators, technological advances vs. user friendliness: the right picture is worth a thousand numbers. Intensive Care Med 2009;35(10):1662-1663.

7. L'Her E, Roy A, Marjanovic N. Bench-test comparison of 26 emergency and transport ventilators. Crit Care 2014;18(5):506.

8. Uzawa Y, Yamada Y, Suzukawa M. Evaluation of the user interface simplicity in the modern generation of mechanical ventilators. Respir Care 2008;53(3):329-337.

9. Vignaux L, Tassaux D, Jolliet P. Evaluation of the user-friendliness of seven new generation intensive care ventilators. Intensive Care Med 2009;35(10):1687-1691.

10. Gonzalez-Bermejo J, Laplanche V, Husseini FE, Duguet A, Derenne JP, Similowski T. Evaluation of the user-friendliness of 11 home mechanical ventilators. Eur Respir J 2006;27(6):1236-1243.

11. Marjanovic N, Le Floch S, Jaffrelot M, L'Her E. Evaluation of manual and automatic manually triggered ventilation performance and ergonomics using a simulation model. Respir Care 2014;59(5): 735-742.

12. Rubio S, Díaz E, Martín J, Puente JM. Evaluation of subjective mental workload: a comparison of SWAT, NASA-TLX, and workload profile methods. Appl. Psychol. 2004;53(1):61-86.

13. Young MS, Brookhuis KA, Wickens CD, Hancock PA. State of science: mental workload in ergonomics. Ergonomics 2015;58(1): 1-17.

14. Hart S, Staveland L. Development of NASA-TLX (task load index): results of empirical and theoretical research. Adv Psychol 1988;52: 139-183.

15. Hart SG. Nasa-Task Load Index (NASA-TLX): 20 years later. Proc Hum Factors Ergon Soc Ann Meet 2006;50(9):904-908.

16. Chatburn RL, El-Khatib M, Mireles-Cabodevila E. A taxonomy for mechanical ventilation: 10 fundamental maxims. Respir Care 2014; 59(11):1747-1763.

17. National Research Council. To err is human: building a safer health system. Washington, DC: National Academies Press; 2000.

18. Boussen S, Gainnier M, Michelet P. Evaluation of ventilators used during transport of critically ill patients: a bench study. Respir Care 2013;58(11):1911-1922.

19. Horsky J, Zhang J, Patel VL. To err is not entirely human: complex technology and user cognition. J Biomed Inform 2005;38(4):264266.

20. Buckle P, Clarkson PJ, Coleman R, Ward J, Anderson J. Patient safety, systems design and ergonomics. Appl Ergon 2006;37(4):491500 .

21. Noyes JM, Bruneau DPJ. A self-analysis of the NASA-TLX workload measure. Ergonomics 2007;50(4):514-519.

22. Boussen S, Gainnier M, Michelet P. Evaluation of ventilators used during transport of critically ill patients: a bench study. Respir Care 2013;58(11):1911-1922. 